\title{
Oil Price Uncertainty and Manufacturing Production
}

\author{
Goodness C. Aye Vincent Dadam $^{\dagger} \quad$ Rangan Gupta ${ }^{\dagger \dagger} \quad$ Bonginkosi Mamba $^{\dagger}$
}

\begin{abstract}
Given the rapid rise and volatility of oil prices, the paper investigates the effect of oil price uncertainty on the South African manufacturing production using monthly observations covering the period 1974:02 to 2012:12. In addition, we quantify the responses of manufacturing production to positive and negative oil price shocks. We examine the dynamic relationship using a bivariate GARCH-in-mean VAR simultaneously estimated with a full information maximum likelihood technique. The conditional standard deviation of the forecast of the growth of US crude oil imported acquisition cost by refiners is used as a measure of oil price uncertainty. Our results show that oil price uncertainty negatively and significantly impacts on South Africa's manufacturing production. We also find that the responses of manufacturing production to positive and negative shocks are asymmetric.
\end{abstract}

JEL codes: C32, D24, E23, E32

Keywords: Oil volatility, Vector autoregression, Bivariate GARCH-in-mean VAR, Manufacturing production.

†University of Pretoria, Department of Economics, Pretoria, South Africa, Email: goodness.aye@gmail.com

†University of Pretoria, Department of Economics, Pretoria, South Africa, Email: dadamvince@yahoo.fr

${ }_{\dagger}+$ University of Pretoria, Department of Economics, Pretoria, South Africa, Corresponding Author, Email: rangan.gupta@up.ac.za

†University of Pretoria, Department of Economics, Pretoria, South Africa, Email: bonginkosi.mamba@gmail.com 


\section{Introduction}

The world has seen sharp increases in oil price that largely impacted on economic growth of many emerging economies in recent years. It is argued that since the 1980s, oil prices have increased in real terms which adversely affected GDP, particularly of oil importing economies. The rapid rise and volatility in oil prices, which started during the early 2000's significantly created great concerns amongst investors over macroeconomic variables such as real gross domestic product (GDP), savings/investment capacity and employment (Nkomo, 2006a). Kohler (2006) warns that such persisting sharp increases in oil prices will adversely affect economies across the world. Elder and Serletis (2010) present the theoretical channels through which oil price shocks affect economic activities. They first identify the real balances and monetary policy channel through which an increase in oil price tends to increase the overall level of prices leading to a reduction in real money balances held by households and firms and ultimately aggregate demand. They also argue that the second channel - the income transfer channel - emphasizes the transfer of income from oil importing countries to oil exporting countries associated with oil price increases.

The 2008/09 global financial crisis resulted in severe structural inefficiencies on many African economies. During this period, the South Africa's manufacturing sector contracted with 10.4 percent, losing about R31 billion in GDP (2005 constant prices). Furthermore, the sector shed over 200000 job opportunities. Positive oil shocks were also witnessed during the crisis which compelled a number of developing economies to adjust their structural reforms, particularly domestic petroleum pricing system which formed a critical component of macroeconomic policies. The South African manufacturing sector relies heavily on energy and oil which is largely imported from Middle East and West African countries. It is against this view that spikes in oil prices would likely impact on manufacturing production hence the overall GDP. Nour (2011) argues that too much dependence on oil may pose challenges to policy makers, through uncertainty in domestic growth given a very volatile international oil market.

Historical data indicate that prior to the 1970s, the price of oil had been fairly stable. However in the 1970s, there was a budge towards a sharp increase in oil prices, shooting to over $\$ 40$ a barrel and by end of the decade, it became even more volatile, rising above $\$ 100$ a barrel (at current prices). The price of oil continued to be volatile but significantly declined to as low as $\$ 20$ in the 1980 s and these low prices were observed till the end of 2001. However, towards the end of 2007 the price of oil started accelerating again, rising sharply in the onset of 2008-2009 recession recording an all-time high of $\$ 145$ a barrel (Hamilton, 2009). The discourse on volatility in oil prices having effect on macroeconomic components such as real GDP and Inflation has been a pertinent issue. The literature on the effect of oil price shocks on economic activities has grown quite large in recent years and early work by Hamilton (1988), Mork (1989), Lee et al. (1995), and Hooker (1996), indicate a negative relationship between oil price shocks and economic activities.

Their results are also confirmed by Hamilton (2009), who investigated the effects of these oil price fluctuations on the US macroeconomic components during the oil shock period of 2007-2008. Hooker 
(2002) also argues that oil shocks significantly contributed to the U.S. core inflation and productivity before 1981. Such studies are also supported by Barsky and Kilian $(2002,2004)$ and Edelstein and Kilian (2007a, 2007b) who further extended their empirical study by investigating oil price shocks on nonresidential fixed investment. The researchers purport that oil price shocks may affect this particular economic activity through a "supply channel" in which an increase in the cost of production, driven by an increase in real oil prices in-turn decreases production (demand channel).

A similar conclusion was derived from a recent study by Elder and Serletis (2010), who estimated a model with disaggregated measures of investments and they found that oil price uncertainty negatively and significantly impacts on real output. They show that volatility in oil prices negatively affect manufacturing production given that firms' decisions to invest are clouded by doubts and uncertainties about future returns. In their study, they conducted an analysis on "real option" models where they analysed firms expenditure patterns given the uncertainty of future returns and they found that volatility in oil prices tend to depress some components of aggregate investment. The real option theory states that firms' decisions to invest in an uncertain future return environment is either delayed or in some instances abandoned as uncertainty about the future returns intensifies. It is a widely accepted phenomenon that most firms fall under this category as their investment and production decisions are frequently influenced by potential future returns; for example, production levels in the automotive industry are driven by positive sales 'outlook as they do not only incur non-recoverable human capital associated costs (hiring and training labour) but also physical capital expenditure (equipment and machinery). Hamilton (2009), states that the immediate effects of oil price changes significantly impact on purchases of motor vehicles which further result in the reduction of income for both buyers and sellers (manufacturers) of vehicles. Given these factors contributing to investment decisions, manufacturers will then choose to lower production rather than employing a complete exit strategy when faced with uncertainty of future returns. Such a stance is also echoed by research conducted by Bernanke (1983) and Pindyck (1991) who argue that volatility in oil prices creates uncertainty about future oil prices hence firms tend to irreversibly postpone their investment decisions. Their results have recently been backed up by Lee et al (2011) who estimated an equation of oil price shocks on firms' investment decisions by exploring U.S. manufacturing data with over 3000 firms. Lee et al (2011) results maintain that firm stock price volatility accompanied by future oil price uncertainty, adversely impact firms' investment decisions for at least the first and second year of the initial shock.

A large number of studies on the impact of oil prices in South Africa have also been conducted by researchers such as Dagut (1978); Kantor and Barr (1986); Van de Merwe and Meijer (1990); Wakeford (2006). The authors mostly focused on the effects of the shocks on domestic inflation, the gold price and the terms of trade. A computable general equilibrium model study which simulated the economy-wide and sectoral impacts of an oil price hike has also been undertaken by PROVIDE (2005). Swanepoel (2006) then extended this analysis by employing a vector autoregressive (VAR) model to examine the impact of three external shocks that included oil prices on South African rates of import, producer and consumer inflation. 
According to Swanepoel (2006), oil shocks slightly, positively impacted on these prices. Bellamy (2006) also attempted a similar study using a VAR framework and he finds that the gold price played a significant role in controlling the negative effects from increasing oil prices. Furthermore, Fofana, et al. (2007; 2008), Nkomo (2006a; 2006b), and Wakeford (2006) also analysed the South African economy and they contend that rising oil prices adversely impact on country's economic performance through various activities such as a surge in total import bill, contraction in exports, acceleration in inflation and domestic interest rates.

As crude oil prices continue to accelerate, there is a renewed concern on its impact on emerging economies. It is argued that oil price shocks widely and negatively impact across sectors and industries (Essama-Nssah, et al, 2007). It is worth noting that different (macro and micro-economic) approaches and methodologies have been employed in assessing the effects of oil price shocks - Richardson, (1988), Faruqee et al., (1998) and IEA, (2009). This paper overlaps with the previous studies by analyzing the effects of oil price shock specifically on manufacturing production which is considered the main driver of employment in South Africa. In this paper, we extend the analysis by Elder and Serletis (2010) and previous studies in South Africa by empirically investigating the response of a real oil price shock on manufacturing production in the South African context. Further, we consider the asymmetric effects of oil price uncertainty unlike the previous South African studies.

Previous studies that use the standard VAR framework do not account for volatilities. These studies implicitly assume that history must always repeat itself. In reality however, history has been proven to include different volatilities at different time intervals as well as time varying volatility (Fama, 1965; Orhan and Koksal, 2012). The GARCH model introduced by Bollerslev (1986) is capable of handling such problems of clustering in time series data. Therefore, this study employs an empirical model that simultaneously estimates the parameters of interest in an internally consistent fashion, which is based on a structural VAR that is modified to accommodate bivariate GARCH-in-Mean errors, as described in Engle and Kroner (1995) and Elder $(1995,2004)$. The model has the desirable property of encompassing homoskedasticity as a special case, so that if the true data generating process is homoskedastic, this will be reflected in the parameter estimates (Elder, 2004). The multivariate GARCH-in-Mean (MGARCHin-Mean) models of which the bivariate one is a special case allow the conditional variance of one or more variables in a simultaneous equations system to impact the conditional mean of one or more other variables (Elder, 2003). Such feedback effects cannot be captured by the standard homoskedastic VAR mainly used in analysing the impact of oil prices, which assumes that the conditional variance is invariant over time. This is because an impulse-response function for the usual homoskedastic VAR will estimate the dynamic response of macroeconomic variables to an oil price shock, accommodating interaction between the conditional means of the variables in the system. However, suppose oil price display evidence of GARCH, so that an oil price shock tends to increase current and future oil price volatility. If oil price volatility, in turn, affects the level of manufacturing production which is the variable of interest in this study, then this is another channel through which an oil price shock affects manufacturing production - a channel that can 
be accommodated by an MGARCH-in-Mean VAR. To summarise this point, an MGARCH-in-Mean VAR would accommodate the usual channel through the conditional means of the variables in the system-but it would also accommodate the effects of the oil price shock on oil price volatility, and, in turn, the effects of oil price volatility on manufacturing production or any real economic activity whereas the standard homoskedastic VAR will accommodate the first channel only. Further, the MGARCH-in-Mean VAR is less ad hoc than single-equation reduced forms and mitigates the effects of simultaneity and generated regressors prevalent in low order dynamic models and two-step estimation methodologies, which may lead to inefficient, inconsistent and/or biased estimates of the parameters of interest (Elder, 2004).

\section{The Empirical Model}

The empirical model we use is a bivariate monthly model in the manufacturing production growth and the real price of oil growth following the primary model developed by Elder $(1995,2004)$. The model is based on a structural VAR with modifications for conditional heteroskedasticity in the parametric form of multivariate GARCH-in-Mean. The main assumption lies in that the dynamics of the structural system can be summarised by a linear function of the variable of interest plus a term related to the conditional variance. We may therefore write:

$$
\mathbf{B} \mathbf{y}_{t}=\mathbf{C}+\boldsymbol{\Gamma}_{1} \mathbf{y}_{t-1}+\boldsymbol{\Gamma}_{2} \mathbf{y}_{t-2}+\ldots+\boldsymbol{\Gamma}_{p} \mathbf{y}_{t-p}+\boldsymbol{\Lambda}(\mathbf{L}) \mathbf{H}_{t}^{1 / 2}+\varepsilon_{t}
$$

where $\operatorname{dim}(\mathbf{B})=\operatorname{dim}\left(\boldsymbol{\Gamma}_{i}\right)=(N \mathrm{x} N), \varepsilon_{t} \mid \psi_{t-1} \sim \operatorname{iidN}\left(\mathbf{0}, \mathbf{H}_{t}\right), \mathbf{H}_{t}^{1 / 2}$ is a diagonal, $\boldsymbol{\Lambda}(\mathbf{L})$ is a matrix polynomial in the lag operator, and $\psi_{t-1}$ denotes the information set at time $t-1$, which includes variables dated $t-1$ and earlier. By assuming that the structural disturbances $\varepsilon_{t}$ are contemporaneously (and conditionally) uncorrolated and by imposing a sufficient number of exclusion restrictions on the matrix $\mathbf{B}$, the system can be identified. The above specification allows the matrix of conditional standard deviations $\left(\mathbf{H}_{t}^{1 / 2}\right)$ to affect the conditional mean, therefore allowing us to test whether oil price volatility affects the real economic activity by examining the appropriate element of $\boldsymbol{\Lambda}$. That is, if oil price volatility has adversely affected output growth, then we would expect to find a negative and statistically significant coefficient on the conditional standard deviation of oil in the output equation. In this paper, the vector $\mathbf{y}_{t}$ includes manufacturing production growth and the real oil price growth.

The conditional variance $\mathbf{H}_{t}$ is modeled as bivariate GARCH which a general version is presented in Bollerslev et al. (1986) and Engle and Kroner (1995) as follows:

$$
\mathbf{h}_{t}=\mathbf{C}_{\mathbf{v}}+\sum_{j=1}^{J} \mathbf{F}_{j} \operatorname{vec}\left(\varepsilon_{t-j} \varepsilon_{t-j}^{,}\right)+\sum_{i=1}^{I} \mathbf{G}_{i} \mathbf{h}_{t-i}
$$

$$
\mathbf{z}_{t} \sim \operatorname{iidN}(\mathbf{0}, \mathbf{I})
$$


$\varepsilon_{t}=\mathbf{H}_{t}^{1 / 2} \mathbf{z}_{t}$ where $\mathbf{C}_{\mathbf{v}}$ is $N^{2} \mathrm{x} 1, \mathbf{F}$ and $\mathbf{G}$ are $N^{2} \mathrm{x} N^{2}$, and $\mathbf{h}_{t}=v e c\left(\mathbf{H}_{t}\right)$. This specification does not however ensure a positive definite $\mathbf{H}_{t}$.

Imposing a common identifying assumptions in structural VARs simplifies greatly the variance function written in terms of the structural disturbances (Elder, 2004). Therefore assuming a zero contemporaneous correlation of structural disturbances, the conditional matrix $\mathbf{H}_{t}$ is thus diagonal, reducing the requisite number of variance functions parameters quite substancially. By re-dimensioning the variance function parameter matrices $\mathbf{C}_{\mathbf{v}}, \mathbf{F}$ and $\mathbf{G}$, we can reduce the variance function to:

$$
\operatorname{diag}\left(\mathbf{H}_{t}\right)=\mathbf{C}_{\mathbf{v}}+\sum_{j=1}^{J} \mathbf{F}_{j} \operatorname{diag}\left(\varepsilon_{t-j} \varepsilon_{t-j}^{\prime}\right)+\sum_{i=1}^{I} \mathbf{G}_{i} \operatorname{diag}\left(\mathbf{H}_{t-i}\right)
$$

where diag is the operator that extracts the diagonal from a square matrix. By assuming that the conditional variance of $y_{i, t}$ depends only on its own past squared errors and its own past conditional variances, the parameter matrices $\mathbf{F}_{j}$ and $\mathbf{G}_{i}$ are thus diagonal as well.

The bivariate GARCH-in-Mean VAR model is thus given by equations (1) and (3) which we estimate by full information maximum likelihood (FIML). Elder and Serletis (2010) argue that doing so avoids Pagan's (1984) generated regressor problems associated with estimating the variance function parameters seperately from the conditional mean parameters. FIML suggests the maximisations of the log likelihood $\sum_{t=1}^{T} l_{t}$ with respect to the structural parameters $\mathbf{B}, \mathbf{C}, \boldsymbol{\Gamma}_{1}, \boldsymbol{\Gamma}_{2}, \ldots, \boldsymbol{\Gamma}_{p}, \boldsymbol{\Lambda}, \mathbf{F}$, and $\mathbf{G}$, where

$$
l_{t}=-(N / 2) \ln (2 \pi)+1 / 2 \ln |\mathbf{B}|^{2}-1 / 2 \ln \left|\mathbf{H}_{t}\right|-1 / 2\left(\varepsilon_{t}^{\prime} \mathbf{H}_{t}^{-1} \varepsilon_{t}\right)
$$

Following Elder and Serletis (2010) we set the pre-sample values of the conditional variance matrix $\mathbf{H}_{0}$ to their unconditional expectation and condition on the pre-sample values $y_{0}, y_{t-1}, \ldots, y_{t-p+1}$. Also, we impose the following restrictions to ensure that $\mathbf{H}_{t}$ is positive defined and $\varepsilon_{t}$ is covariance stationary: $\mathbf{C}_{\mathbf{v}}$ is element-wise positive, $\mathbf{F}$ and $\mathbf{G}$ are element-wise nonnegative, and the eigenvalues of $(\mathbf{F}+\mathbf{G})$ are less than one in modulus. Given that the standard regularity conditions hold, FIML estimates are asymptotically normal and efficient, with asymptotic variance matrix given by the inverse of the Fisher's information matrix.

A primary tool of VAR analysis is the impulse response function which simulates the effects of a shock to one variable in the system on the conditional forecast of another variable. In this study, we calculate the impulses for the GARCH-in-Mean VAR following Elder (2003). Consider an infinite order moving average representation of a reduced form VAR:

$$
\mathbf{y}_{t+k}=\boldsymbol{\theta}(\mathbf{L}) \cdot\left(\mathbf{C}_{0}+\mathbf{\Pi}_{0} \mathbf{H}_{t+k}+\mathbf{B}^{-1} \varepsilon_{t+k}\right)
$$


where $\mathbf{C}_{0}=\mathbf{B}^{-1} \mathbf{C}, \boldsymbol{\Pi}_{0}=\mathbf{B}^{-1} \boldsymbol{\Lambda}, \boldsymbol{\theta}(\mathbf{L})$ is a matrix polynomial in the lag operator. The impulseresponse function can then be derived as the revision in the econometrician's forecast of $\mathbf{y}_{j, t+k}$ in response to a shock to $\varepsilon_{i, t}$,

$$
\frac{\partial E\left(\mathbf{y}_{j, t+k} \mid \boldsymbol{\varepsilon}_{i, t}, \Psi_{t-1}\right)}{\partial \boldsymbol{\varepsilon}_{i, t}}=\sum_{\tau=0}^{k-1} \frac{\partial\left[\boldsymbol{\theta}_{\tau} \mathbf{B}^{-1} \Lambda(\mathbf{F}+\mathbf{G})^{k-\tau-1} \mathbf{F} \cdot E\left(\varepsilon_{t} \varepsilon_{t}^{\prime} \mid \varepsilon_{i, t}, \Psi_{t-1}\right]\right.}{+\frac{\partial E\left(\boldsymbol{\theta}_{k} \mathbf{B}^{-1} \varepsilon_{t}\right)}{\partial \boldsymbol{\varepsilon}_{i, t}}}
$$

Equation (6) is the expression for an impulse response function that is analogous to the impulse response function of an orthogonalized VAR. $\Psi_{t}$ is the information set at time $t$. The second term on the RHS of equation (6) captures the direct effect of a shock $\varepsilon_{i, t}$ on the conditional forecast of $y_{j, t+k}$, and is analogous to the impulse response from the conventional homoscedastic VAR. The first term on the RHS of equation (6) captures the effect on the conditional forecast of $y_{j, t+k}$ through the forecasted effect on the conditional variance. The usual practice is to shock by some magnitude, usually one standard deviation, and to simulate the responses implied by the model (Elder, 2004).

Error bands for the impulse response functions are constructed using the Monte Carlo method, as described in Hamilton (1994, p.337). That is, we simulate the impulse responses from the maximum likelihood estimates of the model's parameters. Confidence intervals are then generated by simulating 1,000 impulse responses based on parameter values drawn randomly from the sampling distribution of the maximum likelihood estimates, where the covariance matrix of the maximum likelihood estimates is derived from an estimate of the Fisher's information matrix.

By imposing identifying procedure in VARs, we can estimate $N(N-1) / 2$ free parameters in $\mathbf{B}$ subject to a rank condition; meaning we can therefore estimate one free parameter in B for a bivavriate VAR. To do so, we follow Kilian and Vega (2009) and Elder and Serletis (2010) and allow the real output growth rate to respond to contemporaneous innovations in the change in the real oil price.

\section{Data and Empirical Results}

We use monthly observations covering the period 1974:02 to 2012:12 to estimate a two-variable simultaneous equations system. The paper also employed US crude oil imported acquisition cost by refiners which we obtain from the US Energy Information Administration as a measure for oil price. Oil price is then divided by CPI US to obtain real terms values since economic theory suggests that real rather than nominal oil price should be considered particularly when making economic decisions. This price index is a weighted average of domestic and imported crude oil costs. It also includes transportation and other fees that refiners pay, therefore measuring the price of crude as an input to production. We keep the price of oil in US Dollars similar to Baumeister and Peersman (2009) study on the consequences of oil shocks as they differ across countries and time. Our measure of uncertainty is the conditional standard deviation of 
the one-step-ahead forecast error of the change in the real price of oil. This is consistent with the definition in Elder $(1994,2004)$ and Elder and Serletis (2010). Output on the other hand is measured by the industrial production for South Africa. We use production in the manufacturing sector which we obtain from the International Monetary Fund's International Financial Statistics (IFS). The series were tested for stationarity using the Dickey and Fuller ( 1981) and Phillips and Perron (1988) unit root tests. The null hypothesis of no unit root cannot be rejected for both series as reported in Table 1. However, the first differenced series are stationary, implying that both series are integrated of order 1, i.e. I(1). Therefore, logarithmic first differences of real oil price and the manufacturing production of South Africa is used. Figure 1 shows the plots of the data we use. The upper panel depicts the series in their log transformed form while the lower panel shows their growth rates (log transformed first differences).

Figure 1: The log and growth rate of oil price and manufacturing production
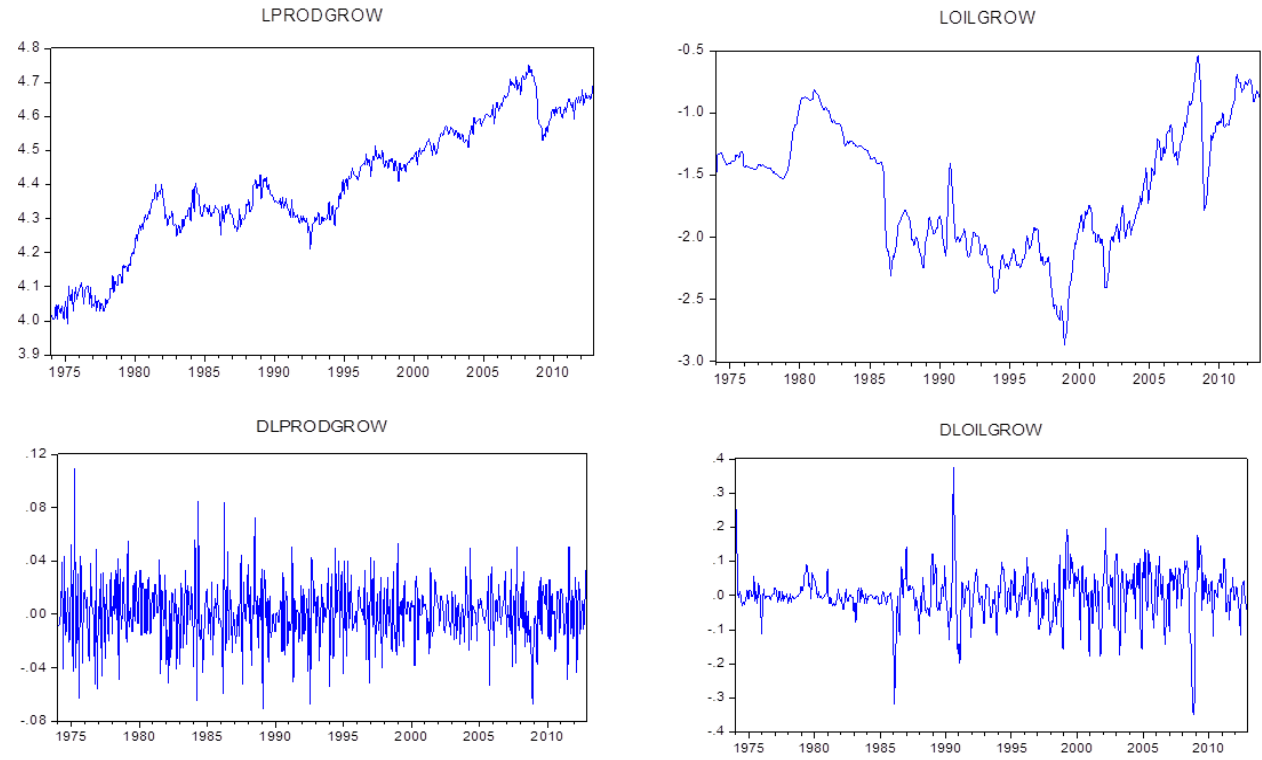

Notes: LPRODGROW: $\log$ of manufacturing production

DLPRODGROW: growth rate of manufacturing production

LOILGROW: $\log$ of oil price

DLOILGROW: growth rate of oil price 
Table 1: Unit root test

\begin{tabular}{|l|l|l|l|l|l|}
\hline \multirow{4}{*}{ Variables } & \multicolumn{4}{c|}{ Level } \\
\hline & \multicolumn{2}{|c|}{ Intercept } & \multicolumn{2}{c|}{$\begin{array}{c}\text { Trend and } \\
\text { intercept }\end{array}$} \\
\cline { 2 - 6 } & ADF & PP & ADF & PP \\
\hline Real Oil Price & -2.37 & -1.84 & -2.35 & -1.82 \\
\hline Manufacturing Production & -1.49 & -1.46 & -2.85 & $-3.68^{* *}$ \\
\hline \multirow{4}{*}{} & \multicolumn{4}{|c|}{ First difference } \\
\cline { 2 - 6 } & \multicolumn{4}{|c|}{ Intercept } & \multicolumn{2}{c|}{ Trend and } \\
& \multicolumn{4}{|c|}{ intercept } \\
\cline { 2 - 6 } & ADF & PP & ADF & PP \\
\hline Real Oil Price & $-13.51^{* * *}$ & $-12.69^{* * *}$ & $-13.52^{* * *}$ & $-12.68^{* * *}$ \\
\hline Manufacturing Production & $-13.1^{* * *}$ & $-34.48^{* * *}$ & $-13.11^{* * *}$ & $-34.46^{* * *}$ \\
\hline
\end{tabular}

Notes: ADF: Augmented Dickey-Fuller test

PP: Phillips-Peron test

*** denotes significance at the $1 \%$ level.

** denotes significance at the $5 \%$ level.

The Akaike Information Criterion (AIC) suggests 6 lags to be sufficient to summarize the dynamics of the system. We therefore estimate a bivariate GARCH-in-mean VAR with 6 lags, using monthly observations. Following Elder and Serletis (2010), we calculated the SIC for the conventional homoskedastic VAR and bivariate GARCH-in-mean VAR. This is to ensure that our specification is consistent with the data. The Schwarz criterion offers a penalty for any additional parameters necessary for estimating the GARCH model and thus an improvement in SIC suggests strong evidence in favor of the model employed. It is evident from Table 2 below that the model captures important features of the data as the values of the conventional homoskedastic VAR of 3751 is greater than the values of the bivariate GARCH-in-mean VAR of 3622 .

Table 2: Model specification test

\begin{tabular}{ccc}
$\begin{array}{c}\text { Bivariate VAR Model } \\
\text { and sample }\end{array}$ & VAR & $\begin{array}{c}\text { Bivariate MGARCH-M } \\
\text { VAR }\end{array}$ \\
\hline Real Oil Price & & \\
Manufacturing Production & 3751 & 3622 \\
$1974.02-2012.12$ & & \\
\hline
\end{tabular}


Furthermore, the point estimates of the variance function parameters of the bivariate GARCH-in-mean VAR are reported in Table 3. Also, the variables in the VAR are ordered as shown in Table 3. This table provides further support for the specification and from the results and one could clearly see that there exists GARCH in manufacturing production and $\mathrm{ARCH}$ in the real price of oil. Analysing it at a monthly frequency, the volatility process for the real price of oil appears not very persistent given that only the coefficient on the lagged squared errors is significant.

Table 3: Coefficient estimates for the variance function of the bivariate Garch-in-mean VAR

\begin{tabular}{lllll} 
Equation & $\begin{array}{c}\text { Conditional } \\
\text { Variance }\end{array}$ & Constant & $\varepsilon_{t}(\mathbf{t}-\mathbf{1})^{2}$ & $\mathbf{H}_{i, i}(\mathbf{t}-\mathbf{1})$ \\
\hline & & & & \\
Real Oil Price & $H_{1,1}(t)$ & $0.55^{* *}$ & $0.95^{* *}$ & 0.00 \\
& & $(8.58)$ & $(17.95)$ & \\
Real Manufacturing Production & $H_{2,2}(t)$ & $2.08^{*}$ & $0.11^{*}$ & $0.4^{*}$ \\
& & $(2.18)$ & $(2.12)$ & $(1.71)$ \\
\hline
\end{tabular}

Notes: These are the parameter estimates for the free elements in $\mathbf{F}$ and $\mathbf{G}$ from the model given by equations (1) and (2) with $\varepsilon_{t} \sim N\left(0, \mathbf{H}_{t}\right)$. Each row in the table represents an equation from the associated bivariate GARCH-in-Mean VAR. Asymptotic t-statistics are in parentheses. A coefficient of 0.00 indicates that the nonnegativity constraint is binding.

** denotes significance at the $5 \%$ level.

* denotes significance at the $10 \%$ level.

Real oil price uncertainty is captured by $\mathbf{H}_{t}^{1 / 2}$. It is the coefficient on the conditional standard deviation of real oil price changes in the output growth equation. We find a negative and statistically significant coefficient of -0.37 . We thus reject the null hypothesis that the true value of that coefficient is zero and we can therefore conclude that uncertainty about real oil price tends to negatively affect manufacturing production in South Africa.

In assessing the effect of real oil price uncertainty on the response of manufacturing production to an oil shock, we simulated the maximum likelihood estimates of the model's parameters. The impulse responses were simulated based on an oil price shock that is equal to the unconditional standard deviation of the change in the real price of oil. Impulse responses of manufacturing production to positive and negative oil price shock were conducted in an attempt to investigate whether these responses are symmetric or asymmetric. The impulse responses (solid lines) with the one-standard deviation error band (dashed lines) are presented in Figure 2. 
Figure 2: Impulse responses for bivariate GARCH-M VAR
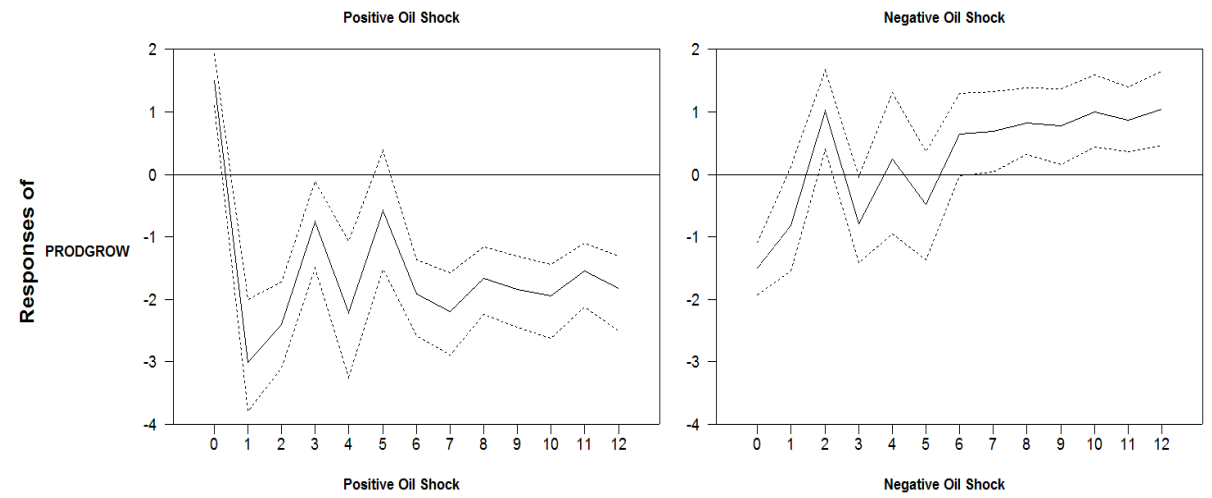

The impulse responses indicate that a positive oil price shock tends to immediately and significantly reduce manufacturing production growth, inducing a downward revision from 1 per cent at the moment of impact to negative 2 per cent in the first month of the initial shock. However, the response remains around the negative territories throughout the year with a slight increase that reaches the zero mean line in the 5th month. Also, it is worth noting that the response of manufacturing production in this case is very volatile in the first 6 months before becoming relatively stable afterward.

On the other hand, response of GDP as measured by the manufacturing production growth to a dynamic negative oil price shock, gradually increases production growth in the first 2 months as it is shown by panel 2 where manufacturing production levels moved from negative to positive territories. Just after the second month one can see that the impact becomes more volatile thus crossing the mean line sideways. Again, this pattern is observed at least up until the 6th month where from then the impact largely remains positive and relatively stable (with a slightly ascending slope) throughout the period.

Judging by the fact that the quantitative effects on manufacturing production of positive and negative oil price shocks are not equal in absolute values, we conclude that the responses are asymmetric.* Finally we plot the impulse responses with and without $\mathrm{M}$ terms in Figure 3. The dashed line depict the manufacturing production response to oil price shock without the $\mathrm{M}$ terms while the solid line depicts the response with the $\mathrm{M}$ terms included in the model. We find that considering the so called $\mathrm{M}$ terms amplifies the responses of manufacturing production to both positive and negative oil price shocks.

* To check for robustness in our results, we have also conducted this study by converting the US crude oil price into South African Rand. The key findings are as follows. Firstly, all the coefficients on the lagged squared errors are significant. The volatility process for the real price of oil is therefore persistent. Secondly, real oil price uncertainty has a significant negative impact on the manufacturing production. We find a significant coefficient of -0.11 . Thirdly, we conclude that the responses of manufacturing production to positive and negative shocks are symmetric. 
Figure 3: Impulse responses with and without $\mathrm{M}$ terms.
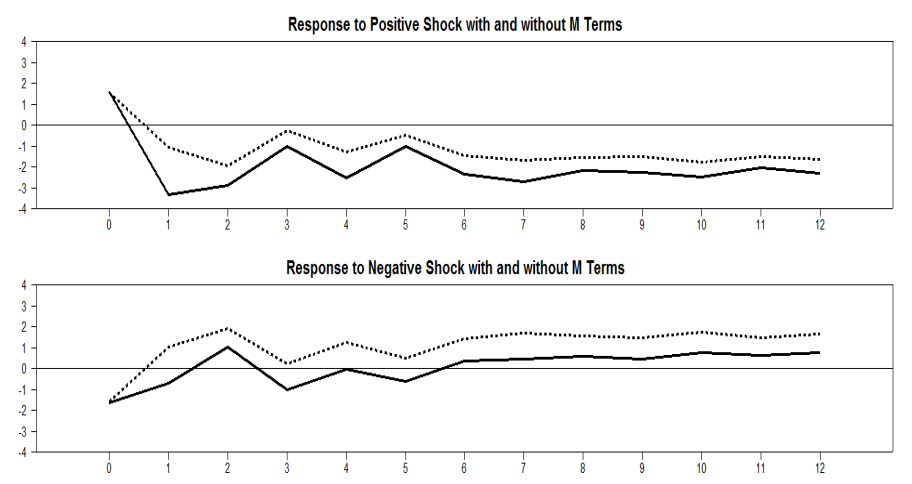

\section{Conclusion}

This paper analyses the effects of oil price uncertainty on the manufacturing production of South Africa since economic theory suggest that uncertainty about the price of oil tend to affect negatively real economic activity. This was achieved through the modified VAR model that accommodates bivariate GARCH-in-Mean errors as described by Elder (1995, 2004). Oil price uncertainty is captured here by the conditional standard deviation of the one-period ahead forecast error of the change in the price of oil.

We find a negative and statistically significant coefficient capturing oil price uncertainty therefore suggesting that uncertainty about oil price negatively impacts on South Africa's manufacturing production. Analysis of the impulse response functions shows that a positive oil price shock reduces significantly manufacturing production in the first month whereas a negative oil price shock slightly reduces production in the first month before having a relatively positive impact onward. The results show that the quantitative responses of manufacturing production to positive and negative oil price shocks are asymmetric.

Overall our findings show that oil price volatility affects affect manufacturing production negatively given that decisions to invest in general and production decisions in particular are often influenced by potential returns. Investors do not only incur human capital related expenditures which are non-recoverable but also physical capital expenditures, some of which are imported. Based on these findings and results from previous South Africa studies (e.g. Swanepoel, 2006; Fofana, et al. 2007; 2008), policies that reduce oil price shocks and volatility will likely contribute to increased manufacturing production and overall economic growth in South Africa. This is because such policies will favour lower import bills and expansion in exports through the exchange rate channel. Moreover, such policies will help to keep the interest rate at a minimal level that will encourage investors to borrow for production. The evidence of asymmetric effect of oil price volatility in this study, may not automatically translate into asymmetries in the propagation mechanism as noted by Kilian and Vigfusson (2011a, 2011b). In other words, reducing oil prices will not necessarily 
increase manufacturing production, because any sharp rise in oil price volatility may crush the positive effect of any reduction in oil prices. Therefore, uncertainty regarding the price of an important input like oil price may affect strategic investment decisions and hence reduce manufacturing production. 


\section{REFRENCES}

Barsky, R. B. \& Kilian, L. 2002. Do we really know that oil caused the great stagflation? A monetary alternative. NBER Macroeconomics Annual, 2001 16, 137-183.

Barsky, R. B. \& Kilian, L.2004. Oil and the macroeconomy since the 1970s. Journal of Economic Perspectives, 18, 115-134.

Baumeister, C., Peersman, G. \& Van Robays, I. 2009. The economic consequences of oil shocks: differences across countries and time. Working Papers of Faculty of Economics and Business Administration, Ghent University, Belgium 09/630, Ghent University, Faculty of Economics and Business Administration.

Bellamy, D. 2006. The macroeconomic effects of the crude oil price on the South African economy. Unpublished Master's Dissertation, University of Cape Town.

Bollerslev, T. 1986. Generalized autoregressive conditional heteroskedasticity. Journal of Econometrics, $31,307-327$.

Bernanke, B. S. 1983. Irreversibility, uncertainty, and cyclical investment. Quarterly Journal of Economics, 98, 85-106.

Bollerslev, T. 1986. Generalized autoregressive conditional heteroskedasticity. Journal of Econometrics, $31,307-27$.

Dagut, M.B. 1978. The economic effect of the Oil crisis on South Africa. South African Journal of Economics, 46:(1)23-35.

Dickey, D.A. and Fuller, W.A., 1981. Distribution of the estimators for autoregressive time series with a unit root. Econometrica 49, 1057-72.

Elder, J. \& Serletis, A. 2010. Oil price uncertainty. Jounal of Money, Credit and Banking, 42, 11381159.

Elder, J. 1995. Macroeconomic and financial effects of monetary policy and monetary policy uncertainty. Ph.D. Dissertation, University of Virginia.

Elder, J. 2003. An impulse response function for a vector autoregression with multivariate GARCH-inMean. Economics Letters, 79, 21-26.

Elder, J. 2004. Another perspective on the effects of inflation volatility. Journal of Money, Credit, and Banking, 36, 911-28.

Edelstein, P.\& Kilian, L. 2007a. Retail energy prices and consumer expenditures. Mimeo, Department of Economics, University of Michigan.

Edelstein, P. \& Kilian, L. 2007b. The response of business fixed investment to changes in energy prices: a test of some hypothesis about the transmission of energy price shocks. B.E. Journal of Macroeconomics, 7,35 .

Engle, R. F. \& Kroner, K. F. 1995. Multivariate simultaneous generalized ARCH. Econometric Theory, $11,122-150$. 
Essama-Nssah , B., et al,. 2007. Economy-wide and distributional impacts of an oil price shock on the South African economy. The World Bank Africa Region, Office of the Chief Economist, September 2007. WPS4354 Public.

Fama, E. F. 1965. The behavior of stock market prices. Journal of Business, 38, 34-105.

Faruqee, H., Isard, P., Laxton, D., Prasad, E. \& Turtelboom, B. 1998. Multimod mark III: the core dynamic and steady state model, IMF Occasional Papers 164, International Monetary Fund.

Fofana, I., Mabugu, R. \& Chitiga, M. 2007. Oil prices and the South African economy: a macromesomicro analysis. Financial and Fiscal Commission Report.

Fofana, I., Mabugu, R. \&Chitiga, M. 2008. Analysing impacts of alternative policy responses to high oil prices using an energy-focused macro-micro model for South Africa. Financial and Fiscal Commission Report.

Hamilton, J. D. 1988. A neoclassical model of unemployment and the business cycle.Journal of Political Economy, 96, 593-617.

Hamilton, J.D. 1994. Time Series Analysis. Princeton University Press, Princeton, NJ.

Hamilton, J. D. 2009. Causes and consequences of the oil shock of 2007-08. University of California, San Diego Brookings Papers on Economic Activity, Spring 2009.

Hooker, M. A. 1996. What happened to the oil price-macroeconomy relationship? Journal of Monetary Economics 38, 195-213.

Hooker, M. A. 2002. Are oil shocks inflationary? asymmetric and nonlinear specifications versus changes in regime. Journal of Money, Credit and Banking, 34, 540-561.

International Energy Agency, (IEA). 2009. World Energy Outlook. Available at [http://www.iea.org/weo/model.asp].

Kantor, B.S. \& Barr, G.D.I. 1986. The impact of a change in the price of petrol on the South African rate of inflation. Journal for Studies in Economics and Econometrics, 26, 35-57.

Kilian, L. \& Vega. 2009. Do energy prices respond to U.S. macroeconomic news? A test of the hypothesis of predetermined energy prices. Review of Economics and Statistics.

Kilian, L. and R.J. Vigfusson. 2011a. Nonlinearities in the oil price-output relationship. Macroeconomic Dynamics, 15(S3), 337-363.

Kilian, L. and R.J. Vigfusson. 2011b. Are the responses of the U.S. economy asymmetric in energy price increases and decreases? Quantitative Economics, 2(3), 419-453.

Kohler, P. 2006. The economics of fair trade: for whose benefit? an investigation into the limits of fair trade as a development tool and the risk of clean-washing. IHEID Working Papers 06-2007, Economics Section, The Graduate Institute of International Studies, revised Oct 2006.

Lee, K., Shawn, N. \& Ratti, R. A. 1995. Oil shocks and the macroeconomy: The role of price variability. Energy Journal 16, 39-56.

Lee, K., Kang, W. \& Ratti, R. A. 2011. Oil price shocks, firm uncertainty, and investment. macroeconomic dynamics, 15 (3):416-436. 
Mork, K. A. 1989. Oil and the macroeconomy. When prices go up and down: An extension of Hamilton's results. Journal of Political Economy, 97, 740-744.

Nkomo, J. 2006a. The impact of higher oil prices on Southern African countries. Journal of Energy in Southern Africa, 17(1) .

Nkomo, J. 2006b. Crude oil price movements and their impact on South Africa. Journal of Energy in Southern Africa, 17(4) .

Nour. 2011. Assessment of the impact of oil: opportunities and challenges for economic development in Sudan. African Review of Economics and Finance, 2(2).

Orhan, M. and Köksal, B. 2012. A comparison of GARCH models for VaR estimation. Expert Systems with Applications 39, 3582-3592.

Pagan, A. 1984). Econometric issues in the analysis of regressions with generated regressors. International Economic Review, 25, 221-247.

Phillips, P.C. and Perron, P. 1988. Testing for a unit root in time series regression. Biometrika, 75, $335-346$.

Pindyck, R. H. 1991. Irreversibility, uncertainty, and investment. Journal of Economic Literature, 29, $110-148$.

PROVIDE. 2005. A computable general equilibrium (CGE) analysis of the Impact of an oil price increase in South Africa. PROVIDE Working Paper, 2005:1, Elsenburg, February.

Richardson, P. 1988. The structure and simulation properties of OECD's INTERLINK model. OECD Economic Studies, 10.

Swanepoel, J.A. 2006. The impact of external shocks on South African inflation at different price stages. Journal for Studies in Economics and Econometrics, 30:(1)1-22.

Van der Merwe, E.J. \& Meijer, J.H. 1990. Notes on oil, gold and inflation. SARB Occasional Paper \#2, December.

Wakeford, J. 2006. The impact of oil price shocks on the South African macroeconomy: History and prospects. SARBConference . 